\title{
Beyond spatial and temporal averages: ecological responses to extreme events may be exacerbated by local disturbances
}

Giulia Ghedini ${ }^{1}$, Bayden D. Russell ${ }^{1,2}$, Laura J. Falkenberg ${ }^{1,3}$ and Sean D. Connell ${ }^{1 *}$

\begin{abstract}
Background: The ecological consequences of climate change will be driven by a combination of both gradual and abrupt changes in climatic conditions. Despite growing evidence that abrupt abiotic change of extreme events may profoundly alter ecological processes, it remains unclear how such events may combine with longer-term global and local disturbances. Here, we focused on a key process of herbivory and tested how its strength would change in response to forecasted global $\left(\mathrm{CO}_{2}\right.$ enrichment) and local disturbances (nutrient enrichment) under abrupt (heat wave) or gradual (future temperature) changes in temperature, using an herbivorous gastropod and turf algae interaction within kelp forests as a model system.

Results: The heat wave caused the greatest magnitude of change in consumption across all treatment combinations. The positive effect of nutrient enrichment on consumption was magnified by increasing temperature, but caused surprisingly intense herbivory when combined with the heat wave. Carbon and nutrient enrichments individually increased consumption with nitrogen overriding the positive effects of $\mathrm{CO}_{2}$.

Conclusions: These results not only reveal that the strength of ecological responses to extreme events may substantially exceed those manifested under 'average' future conditions, but also that the effects of extremes may be exacerbated by local disturbances. If disproportionate ecological change occurs where extreme events overlap with local disturbances, scientists and managers will need to recognize spatial and temporal heterogeneities of environmental change to think beyond averages.
\end{abstract}

Keywords: Climate, Temperature, Ocean acidification, Eutrophication, Heat wave, Disturbance, Herbivory

\section{Background}

Climate change is driven by both the consequences of gradual changes in climatic conditions (i.e. 'trends') and also their increased variability (i.e. 'events') $[1,2]$. There is growing consensus on the importance of understanding ecological responses to 'events' rather than 'trends' as climate extremes may drive profound ecological changes over short-time scales [3-5]. Extreme events represent discrete, pulse disturbances that cause abrupt changes to the abiotic environment relative to the life cycle of most organisms or ecological processes [2]. Hence, such short-term extreme variation in climatic

\footnotetext{
* Correspondence: sean.connell@adelaide.edu.au

'Southern Seas Ecology Laboratories, School of Biological Sciences and The Environment Institute, The University of Adelaide, DX 650 418, Adelaide 5005SA, Australia

Full list of author information is available at the end of the article
}

conditions can be biologically more significant than longer-term trends of change to which organisms have greater probability of acclimation, adaptation and, ultimately, evolution $[2,6,7]$.

Evidence of the importance of climate extremes as drivers of ecosystem dynamics, structure and function is increasing through field observations and experimental studies [8-13], although the severity of the impacts of extreme events remains variable [9]. Despite the potential ecological importance of extremes, most climate change research, particularly in the marine environment, remains focused on average trends of change (but see [5, $12,13])$. Hence, our understanding of ecological responses to extreme and abrupt changes in abiotic conditions remains poorly developed [14]. Since extreme events are becoming increasingly common and intense $[15,16]$ and their ecological effects on communities can 
be significant $[9,12]$, we need to move beyond trendbased studies to include studies of 'events'.

Changes in climate are, however, not occurring in isolation from other human-driven disturbances. Notably, extreme events will interact with longer-term local and global stressors to drive change [14, 17, 18]. As ecological responses are often driven by small-scale variability in environmental conditions, efforts to manage and conserve natural communities in the face of increasing abiotic change require consideration of how global and local stressors may combine to drive ecological change $[14,19]$. Hence, establishing the nature of interactions between multiple stressors acting at different spatial and temporal scales is critical to build a more accurate framework to predict the ecological consequences of an increasingly variable environment $[20,21]$. Whilst the importance of studying stressors in combination, rather than their individual effects, has long been recognized and research has been moving towards studies of multiple stressors [22-24], the combined effects of climate extremes with other disturbances remain very much unexplored [25].

Coastal areas are particularly vulnerable to such interactions as they often experience combinations of changes in climatic conditions (e.g. temperature, $\mathrm{CO}_{2}$ enrichment) and local stressors (e.g. nutrient enrichment) $[23,26,27]$. Moreover, shallow coastal areas are not only exposed to gradual changes in temperature due to warming but also more frequently experience abrupt changes during heat waves [12, 15]. Whilst the effects of warming on individual organisms and trophic interactions are relatively well understood [28-30], such predictions may be complicated in a multi-stressor context.In particular, anticipations of the ecological effects of changing climate may be complicated if the effects of abrupt (i.e. heat waves) or gradual changes in temperature (i.e. long-term predictions) are differentially modulated by co-occurring stressors [31, 32].

Herbivory is an ecological process that rapidly responds to abiotic changes driven by global (e.g. temperature, $\mathrm{CO}_{2}$ ) and local stressors (e.g. nutrients) in terrestrial [33, 34] and aquatic systems [35-37]. As temperature is one of the main determinants of metabolism, predicted changes in temperature are expected to be a focal factor in determining strength of herbivory [28-38]. Whilst long-term warming may increase herbivory mainly by directly enhancing consumer metabolism [29], such effects on consumption can be reduced or even reversed with further increases in temperature [38]. For example, herbivores may reduce consumption rates when temperature increases to values that approach their physiological limits [39]. To complicate predictions, however, is the consideration that rates of herbivory are not only determined by direct effects of abiotic changes, but also by indirect effects mediated by changes in food quality and palatability
[33, 40, 41]. Hence, the effects of temperature on herbivory may be mediated by co-occurring changes in the abiotic environment [41]. For instance, changes in the availability of carbon and nitrogen indirectly modify consumer pressure by altering plant (or algal) composition and nutritional quality, often increasing consumption rates as nitrogen content increases [33, 40, 42]. Therefore, strength of herbivory will ultimately not only be determined by the changes in temperature experienced by consumers (i.e. abrupt vs. gradual) but also by carbon and nitrogen availability in the environment. To date, however, there has been no assessment of how abrupt changes in temperature (i.e. heat waves) may interact with carbon and nitrogen enrichment to alter consumption rates relative to gradual warming scenarios. Therefore, despite the increasing occurrence of heat waves, we are unable to predict the direction and magnitude of changes in herbivory during such events.

Here, we provide an experimental assessment of how abrupt (heat wave) and gradual changes in temperature (predicted future temperature) may differentially interact with long-term global $\left(\mathrm{CO}_{2}\right.$ enrichment) and local stressors (nutrient enrichment) to alter herbivore pressure. Our experimental assessment focuses on a model herbivore-plant interaction between an herbivorous gastropod and turf-forming algae within kelp forests. We predict that changes in herbivory observed under future temperatures will not only differ from those observed during an extreme event, but also that their effects will be differentially mediated by co-occurring global and local disturbances.

\section{Results}

Changes in consumption rates were driven by an interaction between temperature and nutrient treatments as well as by an interaction between $\mathrm{CO}_{2}$ and nutrients (Fig. 1, Table 1, Additional file 1).

Notably, the heat wave event caused the greatest magnitude of change in consumption rates across all treatment combinations (Fig. 1, Table 1). Specifically, under ambient nutrient conditions, the heat wave increased consumption rates between 10 and 20 times relative to the initial control temperature (Fig. 1). The effects of the heat wave were magnified by nutrient enrichment, so that consumption increased up to 40 times relative to initial control rates (Fig. 1). Conversely, the effects of future temperature on consumption were not distinguishable from those of control temperatures (Fig. 1); the Student-Newman-Keuls test, indeed, did not identify any significant change in consumption rates between future and control temperatures (either initial or final control) under either ambient or enriched nutrients (Table 1, Additional file 1). 


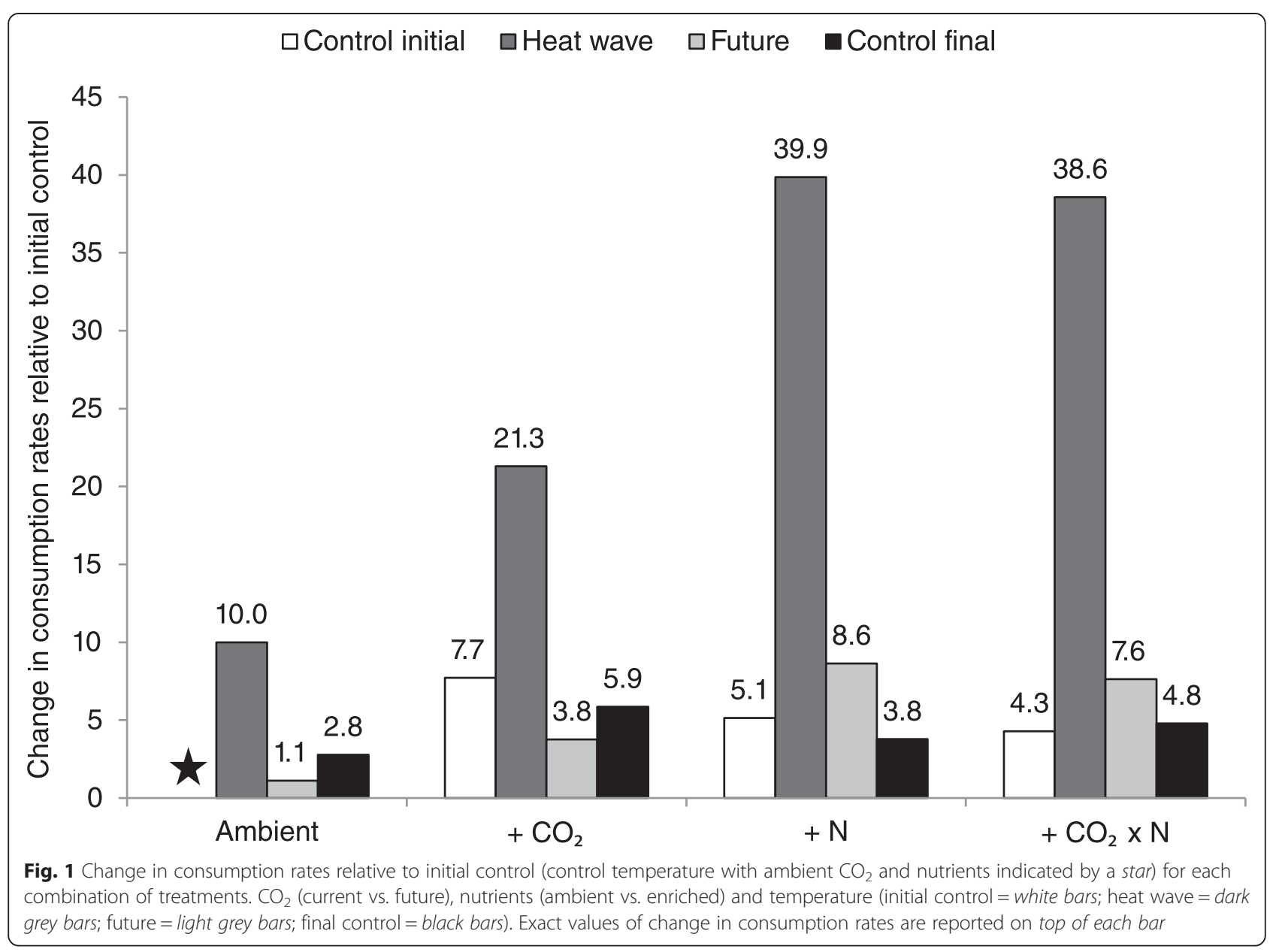

Whilst nutrient enrichment did not alter consumption rates at control temperature (either initial or final control), nutrients significantly increased consumption rates at future temperature and this effect was exacerbated by the heat wave (Table 1, Additional file 1). Consumption rates were not different between ambient and enriched nutrients at both the initial and final control temperatures set at $16{ }^{\circ} \mathrm{C}$ (i.e. the two controls behaved in the same way), but nutrients elevated consumption within future and heat wave treatments (Table 1). The lack of detectable differences between controls of $16{ }^{\circ} \mathrm{C}$ at the beginning and end of the experiment indicated not only that the responses were due to the treatments per se but also that elevated temperatures did not have long-lasting effects on herbivory.

As mentioned above, consumption rates were also altered by an interaction between carbon and nitrogen treatments (Table 1). Whilst carbon enrichment significantly increased consumption rates at ambient nutrient conditions, this effect was not visible in the presence of nutrient enrichment (Fig. 1, Table 1).
Nutrient enrichment significantly increased consumption rates with a stronger effect at ambient rather than enriched $\mathrm{CO}_{2}$ conditions (Fig. 1, Table 1).

\section{Discussion}

Since frequency and intensity of extreme events increase with climate variability [16], abrupt changes in abiotic conditions might become stronger ecological drivers than gradual changes $[2,14]$. Here, we show that the ecological effects of an extreme event (i.e. heat wave) substantially exceeded those of long-term global (i.e. future temperature, $\mathrm{CO}_{2}$ enrichment) and local abiotic changes (i.e. nutrient enrichment). Indeed, the magnitude of change in consumption rates of herbivores caused by the heat wave over a short-time scale (hours) was significantly greater than that elicited by all other experimental conditions (up to 40 times greater than control conditions).

As temperature is a main determinant of consumer metabolism [28, 30], we anticipated that both the heat wave and future temperature treatments would enhance 
Table 1 ANOVA on per capita consumption rates

\begin{tabular}{lllll}
\hline Source & $\mathrm{df}$ & $\mathrm{MS}$ & $\mathrm{F}$ & $p$ \\
Temperature (T) & 3 & 6.95 & 103.28 & $0.0000^{*}$ \\
$\mathrm{CO}_{2}$ & 1 & 0.39 & 5.82 & 0.0187 \\
$\mathrm{~N}$ & 1 & 2.94 & 43.70 & $0.0000^{*}$ \\
$\mathrm{~T} \times \mathrm{CO}_{2}$ & 3 & 0.04 & 0.62 & 0.6048 \\
$\mathrm{~T} \times \mathrm{N}$ & 3 & 1.66 & 24.60 & $0.0000^{*}$ \\
$\mathrm{CO}_{2} \times \mathrm{N}$ & 1 & 0.56 & 8.36 & $0.0052^{*}$ \\
$\mathrm{~T} \times \mathrm{CO}_{2} \times \mathrm{N}$ & 3 & 0.07 & 1.09 & 0.3588 \\
Residual & 64 & & & Heat wave: $+\mathrm{N}>>-\mathrm{N}$ \\
SNK on $\mathrm{T} \times \mathrm{N}$ & & & Future: $+\mathrm{N}>-\mathrm{N}$ \\
Ambient nutrients: $\mathrm{H}>>\mathrm{F}=\mathrm{C}_{1}=\mathrm{C}_{\mathrm{F}}$ & Initial Control: $+\mathrm{N}=-\mathrm{N}$ \\
Enriched nutrients: $\mathrm{H}>>\mathrm{F}=\mathrm{C}_{1}=\mathrm{C}_{\mathrm{F}}$ & & Final Control: $+\mathrm{N}=-\mathrm{N}$ \\
& & & Enriched $\mathrm{CO}_{2}:+\mathrm{N}>-\mathrm{N}$ \\
\hline SNK on $\mathrm{CO}_{2} \times \mathrm{N}$ & &
\end{tabular}

Analyses $(n=5)$ were done for the four levels of temperature (initial control temperature: $\mathrm{C}_{1}$; heat wave: $\mathrm{H}$; future: $\mathrm{F}$; final control: $\mathrm{C}_{\mathrm{F}}$ ), two levels of $\mathrm{CO}_{2}$ (current: $-\mathrm{CO}_{2}$ vs. future: $+\mathrm{CO}_{2}$ ) and two levels of nutrients (ambient: $-\mathrm{N}$ vs. enriched: $+\mathrm{N}$ ). The critical value of significance has been adjusted to $\alpha=0.01$ (see the 'Methods' section). Data were non-transformed. The symbol * denotes terms significant at $\mathrm{a}=0.01$

consumption. Contrary to our predictions, only the heat wave resulted in a significant increase in consumption rates. This result reinforces the notion that extreme events are likely to prompt stronger ecological responses than gradual trends of change and, therefore, deserve a greater research focus $[4,14]$. Whilst gradual changes may allow time for organisms to acclimate and ultimately adapt [2, 7], abrupt changes can rapidly alter the strength of ecological processes by challenging the acclimatory capacity over short periods of time $[2,9]$.

The absence of significant effects of future temperatures on consumption rates suggests that even a relatively short acclimation period (3 months) may be sufficient to allow subtidal gastropod grazers to acclimate to near-future conditions and, thus, show subtle or no ecological changes to such conditions [43]. It is, however, possible that our effects of future warming were minimized by the previously experienced heat wave as grazers were exposed to future temperatures after the heat wave event. Hence, we are cautious not to overstate the absence of effects of gradual warming. Importantly, we detected that the effects of the local stressor (i.e. nutrient enrichment) were differentially mediated by changes in temperature (i.e. control vs. future temperature vs. heat wave). Progressive increases in temperature exacerbated the effects of nutrient enrichment, which caused the strongest increases in consumption rates when combined with the heat wave. These results indicate that abrupt and gradual changes in temperature may differentially mediate ecological responses to co-occurring stressors. Hence, understanding regional and local vulnerability to environmental change requires consideration of how abrupt and gradual changes in abiotic conditions may interact with other stressors acting at different spatial and temporal scales [21, 23, 44].

Importantly, the combined effect of the heat wave and the local stressor caused surprisingly intense herbivory, with a magnitude of change substantially greater than that caused by any other stressor or combination of stressors. If the ecological effects of extreme events are exacerbated by local change (e.g. nutrient pollution), then our ability to anticipate and mitigate the consequences of climate change may be substantially challenged if such interactions are not recognized. In locations with intensive terrestrial-based human activities (e.g. cities or agriculture), in particular those likely to experience more intense and frequent rainfall events, nutrient enrichment from land runoff may accelerate change, particularly when in combination with warmer temperatures $[27,45,46]$. This awareness, however, also empowers local managers as mitigation of the effects of climate extremes may be possible through management of local stressors [21, 27, 47, 48].

Nutrient enrichment is frequently associated with the decrease in water quality along coastal areas [23, 49], where it often interacts in non-additive ways with cooccurring stressors to drive ecological change [23, 27]. Accordingly, we found that nutrient enrichment not only increased consumption with increasing temperature but also interacted with carbon enrichment to alter consumption rates. Variations in carbon and nitrogen availability in the environment are well-known factors in driving changes in consumer pressure by altering the palatability and composition of primary producers [34, 40] as well as through direct effects on consumers [50, 51]. As increases in the nutrient content of algae often drive increases in consumption [40], it is possible that changes in herbivory rates are more strongly influenced by changes in nutrient rather than carbon availability. Similarly, we found that the effects of nutrients on consumption overrode those of carbon enrichment. In contrast, warming often stimulates herbivory by directly increasing the energetic demand of consumers [29, 39]. Although we do not exclude possible indirect effects mediated by algae, the strong increases in consumption that we observed during the heat wave are more likely a consequence of increased consumer metabolism rather than indirect effects. Changes in the composition or nutritional quality of algae, indeed, would seem unlikely given the short duration of the extreme event (i.e. hours).

The intensification of abiotic change due to human activities is expected to increase variation in strength of 
herbivory across regions [29]. Such variation might be driven not only by the combination of stressors locally experienced but also by the rapidity and magnitude of abiotic change. Here, for example, we show that abrupt and gradual abiotic changes may differentially interact with local stressors to alter rates of herbivory in substantially different ways. Changes in top-down pressure can have profound effects on community structure [52], but the community-level implications of such changes are strongly context-dependent and require consideration of both the response of herbivores to specific stressors and the effects of these stressors on primary producers. Where changes in herbivory do not reflect changes in productivity, strong increases in consumption during heat waves may impact primary producers if herbivores consume over short periods of time a substantially greater amount of food than would normally be consumed $[12,53]$. Conversely, where abiotic change stimulates consumption to vary in a proportional way to changes in productivity, increased herbivory can provide a stabilizing mechanism against community change [54]. For example, in the system that we consider, an increase in consumption of turf algae by gastropod grazers can counter the expansion of these weedy species promoted by increasing levels of abiotic change [54]. However, when abiotic change (e.g. temperature) exceeds the physiological tolerance of herbivores, these can become inactive [39, 55] meaning that such compensatory effect may fail as herbivory is strongly suppressed.

Despite the recognized importance of interactions among local and global stressors [22, 56] and of extreme events in driving ecological change [4], we lack a framework to predict the combined effects of climate variability and long-term abiotic change [14, 25]. Hence, forecasting ecological responses to extreme events and how these responses vary depending on interactions with co-occurring stressors remains a major challenge $[5,56]$. The results here presented not only emphasize how interactions among multiple stressors drive variability in ecological responses, but also demonstrate that the ecological effects of extreme events can be profoundly different (and stronger) than the effects of gradual abiotic change. This result is a timely reminder given that much of our understanding of the effects of environmental change remains based on studies of one or two environmental parameters that focus on average change [14].

In conclusion, it is particularly insightful that local change can exacerbate the effects of extreme events. Despite growing recognition that extreme events shape ecological communities $[2,4,12,13]$, their ecological effects remain variable and difficult to anticipate [9]. If disproportionate ecological change occurs where extreme events overlap with local disturbances, scientists and managers will need to recognize spatial and temporal heterogeneity of environmental change to think beyond averages.

\section{Methods}

\section{Experimental protocol}

Gastropod grazers (Turbo undulatus) were collected on a shallow subtidal rocky reef within a kelp forest (O'Sullivan Beach, South Australia, Australia) and, then, acclimated in aquaria at seasonal ambient temperature $\left(16{ }^{\circ} \mathrm{C}\right)$ and experimental levels of $\mathrm{CO}_{2}$ and nutrients (see below for details) for 6 months prior to experiments at the University of Adelaide, South Australia. We had five replicate aquaria (L $40 \times \mathrm{W} 30 \times \mathrm{H} 20 \mathrm{~cm}, 15 \mathrm{~L}$ ) for treatment combination of $\mathrm{CO}_{2}$ (current vs. future) and nutrients (ambient vs. enriched), each aquaria with one grazer $(n=5)$. The aquaria were exposed to full sunlight and its natural daylight cycle. Following acclimation, consumption rates of grazers were measured at different temperature scenarios to which the same grazers were exposed over time (see the 'Temperature treatments' section below, Fig. 2), whilst maintaining constant $\mathrm{CO}_{2}$ and nutrient treatments. During the entire period of acclimation and experiments, grazers were kept in cages $(10 \times 10 \mathrm{~cm}, n=1$ grazer per cage per aquaria) and were fed with turf algae (defined as in [57]) grown on panels $(10 \times 10 \mathrm{~cm})$ in the same experimental conditions that the grazers were exposed to.

\section{$\mathrm{CO}_{2}$ and nutrient treatments}

During the entire duration of the experiment, including the initial 6-month acclimation period, levels of $\mathrm{CO}_{2}$ and nutrients were maintained constant for each treatment. The target partial pressure of $\mathrm{CO}_{2}\left(p \mathrm{CO}_{2}\right)$ was based on the current ambient (current, $400 \mathrm{ppm}$ of $\mathrm{CO}_{2}$ ) and the prediction under the RCP6.0 scenario for the year 2100 for atmospheric $\mathrm{CO}_{2}$ (future, $950 \mathrm{ppm}$ ) [15] (Additional file 2). Elevated $\mathrm{CO}_{2}$ concentrations were maintained by bubbling air with enriched $\mathrm{CO}_{2}$ into the appropriate mesocosms using a Pegas gas mass flow controller (Columbus Instruments, CO, USA), whilst ambient $\mathrm{CO}_{2}$ treatments were maintained by bubbling ambient air. Water $\mathrm{pH}$ NBS was measured daily, and titration was performed during each trial to determine alkalinity using an automated titrator (888 Titrando, Metrohom, USA). Partial pressure of $\mathrm{CO}_{2}$ was calculated from measured $\mathrm{pH}$ NBS, alkalinity, temperature and salinity using the CO2SYS program for Excel [58] with constants from Mehrbach et al. [59] as adjusted by Dickson and Millero [60] (Additional file 2).

Nutrients were enhanced using Osmocote Plus ${ }^{\circ}$ (Scotts) controlled release fertilizer (6 months release: $15 \% \mathrm{~N}, 5 \% \mathrm{P}, 10 \% \mathrm{~K})$, which was placed in nylon mesh bags (1-mm mesh size) and attached to the bottom of mesocosm assigned to enriched nutrient treatments $(5 \mathrm{~g}$ 


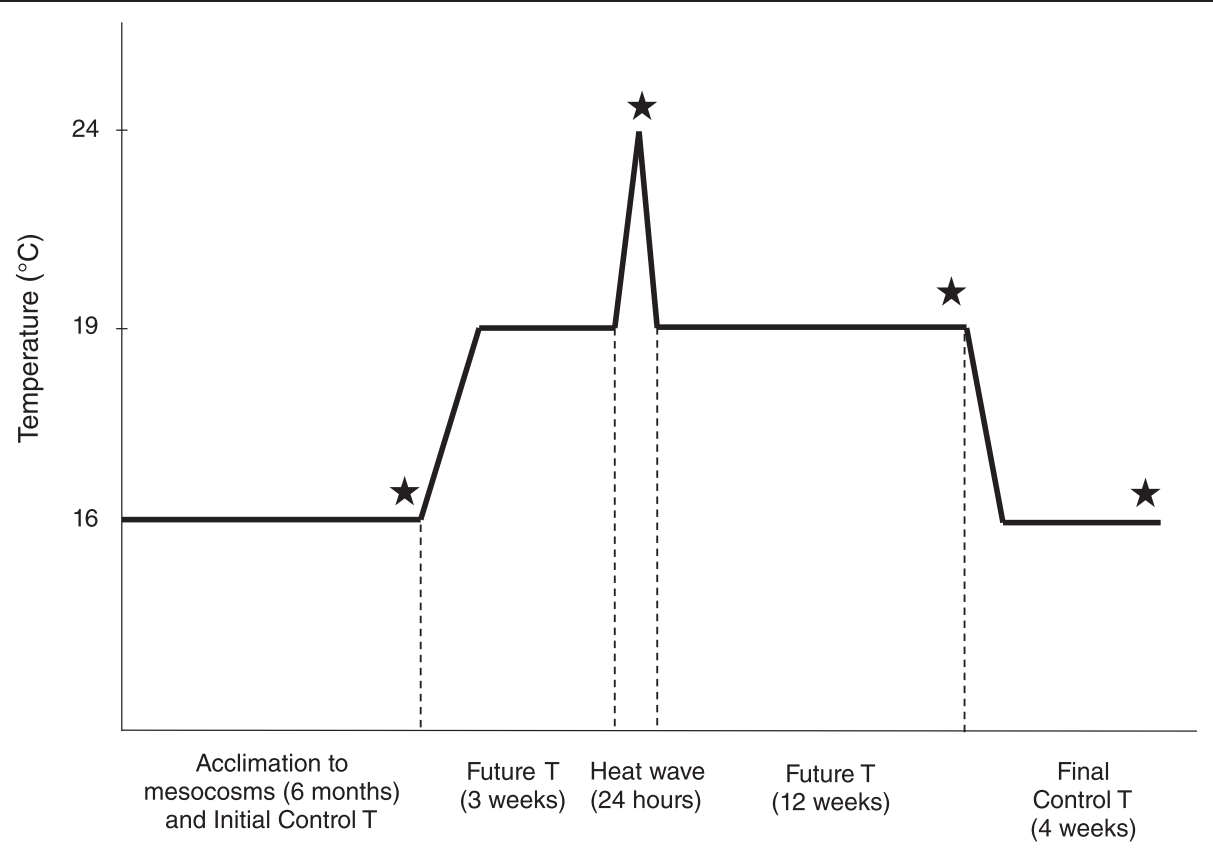

Fig. 2 Order and duration of the experimental temperature treatments: initial control $\left(16^{\circ} \mathrm{C}\right)$, heat wave $\left(24^{\circ} \mathrm{C}\right)$, future temperature $\left(19{ }^{\circ} \mathrm{C}\right)$, final control $\left(16^{\circ} \mathrm{C}\right)$. The stars indicate when rates of consumption of turf algae by grazers were quantified with feeding assays at the end of each experimental temperature period

per mesocosm). These nutrient additions were used to achieve elevated nutrient concentrations which reproduced those of dissolved inorganic nitrogen (DIN) in urban catchments under moderate to heavy rainfall events (DIN $0.55 \pm 0.13 \mathrm{mg} / \mathrm{L}$; enriched nutrients) in contrast to ambient nutrient conditions (DIN $0.09 \pm$ $0.02 \mathrm{mg} / \mathrm{L}$; ambient nutrients) [41], as used in previous experiments [42].

\section{Temperature treatments}

Following the initial 6-month acclimation period at control temperature conditions $\left(16{ }^{\circ} \mathrm{C}\right.$ as average spring/autumn water temperature of South Australia), consumption rates were measured with feeding assays (see the 'Response variables and Analyses' section below) to establish a baseline of consumption rates among the treatments at control temperature (i.e. $16{ }^{\circ} \mathrm{C}$ ) at the start (initial control) and end of the experiment (final control) (See Fig. 2 for experimental design; Additional file 2 for experimental conditions). The analytical inclusion of consumption rates measured at the initial and final control temperatures enabled the identification of treatment effects during the interviewing times (i.e. heat wave and future temperature).

After the initial control, all grazers were gradually acclimated to predicted future average temperature ('future temperature, $19^{\circ} \mathrm{C}$ ) for 3 weeks, representing a three degree increase on top of the control temperature as predicted by global warming trajectories [15]. At the end of this 3-week period, temperature was increased by 4 over a 24-h period (from 19 to $23{ }^{\circ} \mathrm{C}$ ), simulating a heat wave event during which consumption rates were quantified to assess the effects of abrupt abiotic change. The magnitude of change in temperature was comparable to the heat wave described by Wernberg et al. 2013 [12], which was up to $4^{\circ}\left(24^{\circ} \mathrm{C}\right)$ above the high summer temperatures $\left(20^{\circ} \mathrm{C}\right)$ for Western Australia.

Subsequently, temperature was reduced back to the future temperature treatment $\left(19{ }^{\circ} \mathrm{C}\right)$ which was maintained for three consecutive months over summer. Consumption rates were quantified again at the end of this period to assess the effects of long-term warming. Finally, temperature was gradually reduced over a week to the control temperature level $\left(16{ }^{\circ} \mathrm{C}\right)$ at which grazers were maintained for three more weeks prior to quantifying consumption rates to establish a final control.

\section{Response variables and analyses}

Feeding assays were run at the end of each temperature exposure period (initial control, heat wave, future temperature, final control; see Fig. 2) to measure the rate at which grazers consumed turf algae. Each grazer was provided with a fresh panel $(10 \times 10 \mathrm{~cm})$ of turf algae at the start of each feeding assay. Turf cover on the panel was measured at the start and at the end of the feeding assay. Per capita consumption rates were then determined as the percentage cover of turf algae consumed per grazer per hour in each treatment combination of 
temperature, $\mathrm{CO}_{2}$ and nutrients. The duration of feeding essays was of $24 \mathrm{~h}$ for the heat wave (and initial control) and $96 \mathrm{~h}$ for future temperature (and final control). Percentage cover of algae was measured using a quadrat the same dimensions as the panel, divided into 25 subquadrats and assigning between 1 and 4 points in percentage cover to each of the 25 sub-quadrats according to the cover of turf present, so that the total sum would be 100 in a panel completely covered by turfs (as used in [54]). We agree that separating the direct and indirect causes of change in herbivory offers useful insights into the drivers of change, but this analysis would not improve our interpretation as to whether herbivory is modified by extreme events and their interactions with long-term trends and local disturbances.

Feeding rates were compared among temperature, nutrients and $\mathrm{CO}_{2}$ treatments using univariate analyses of variance $(n=5)$. The three factors were treated as fixed and orthogonal with four levels for temperature (initial control, heat wave, future, final control), two for $\mathrm{CO}_{2}$ (current vs. future) and two for nutrients (ambient vs. enriched). These feeding rates were derived from the same individuals within the same temperature treatments that were adjusted through time but crossed with independent combinations of enriched $\mathrm{CO}_{2}$ and nutrients. Hence, our measures of feeding rates are not independent of temperature; this non-independency might have increased the probability of type I error rates because variation between grazers within a treatment is likely to be smaller within temperature treatments than when estimated from independent individuals. To reduce the probability of type I error, therefore, we revised the critical level of alpha from 0.05 to 0.01 [61].

\section{Additional files}

Additional file 1: Consumption rates. (DOCX $22.8 \mathrm{~kb}$ )

Additional file 2: Experimental conditions. (DOCX $23.3 \mathrm{~kb}$ )

\section{Competing interests}

The authors declare that they have no competing interests.

\section{Authors' contributions}

GG, SDC BDR conceived and designed experiments. GG performed the experiments, analysed the data and wrote the manuscript. SDC, BDR and LF assisted with interpretation of results and manuscript feedback. All authors read and approved the final manuscript.

\section{Acknowledgements}

Research funding was provided by an Australian Research Council grant to BDR and SDC. Support was provided by an IPRS Scholarship (University of Adelaide) to GG and an ARC Future Fellowship to SDC. Funds were also provided by a Nature Foundation SA grant and Dr. Paris Goodsell Marine Ecology Research Grant.

\section{Author details}

'Southern Seas Ecology Laboratories, School of Biological Sciences and The Environment Institute, The University of Adelaide, DX 650 418, Adelaide
5005SA, Australia. ${ }^{2}$ Present address: Swire Institute of Marine Science and School of Biological Sciences, The University of Hong Kong, Hong Kong, SAR, China. ${ }^{3}$ Present address: School of Energy and Resources, University College London, Adelaide 5005SA, Australia.

Received: 3 August 2015 Accepted: 7 September 2015

Published online: 30 September 2015

\section{References}

1. Easterling DR, Meehl GA, Parmesan C, Changnon SA, Karl TR, Mearns LO. Climate extremes: observations, modeling, and impacts. Science. 2000;289(5487):2068-74. doi:10.1126/science.289.5487.2068.

2. Jentsch A, Kreyling J, Beierkuhnlein C. A new generation of climate-change experiments: events, not trends. Fron Ecol Environ. 2007;5(7):365-74. doi:10.1890/1540-9295(2007)5[365:ANGOCE]2.0.CO;2.

3. Jentsch A, Kreyling J, Elmer M, Gellesch E, Glaser B, Grant K, et al. Climate extremes initiate ecosystem-regulating functions while maintaining productivity. J Ecol. 2011;99(3):689-702. doi:10.1111/j.1365-2745.2011.01817.x.

4. Thompson RM, Beardall J, Beringer J, Grace M, Sardina P. Means and extremes: building variability into community-level climate change experiments. Ecol Lett. 2013;16(6):799-806. doi:10.1111/ele.12095.

5. Smale DA, Yunnie ALE, Vance T, Widdicombe S. Disentangling the impacts of heat wave magnitude, duration and timing on the structure and diversity of sessile marine assemblages. PeerJ. 2015;3:e863. doi:10.7717/peerj.863.

6. Gutschick VP, BassiriRad H. Extreme events as shaping physiology, ecology, and evolution of plants: toward a unified definition and evaluation of their consequences. New Phytol. 2003;160(1):21-42. doi:10.1046/j.14698137.2003.00866.x

7. Veilleux HD, Ryu T, Donelson JM, van Herwerden L, Seridi L, Ghosheh $Y$ et al. Molecular processes of transgenerational acclimation to a warming ocean. Nature Clim Change. 2015. doi:10.1038/nclimate2724.

8. Gaines SD, Denny MW. The largest, smallest, highest, lowest, longest, and shortest: extremes in ecology. Ecology. 1993;74(6):1677-92. doi:10.2307/ 1939926.

9. Smith MD. An ecological perspective on extreme climatic events: a synthetic definition and framework to guide future research. J Ecol. 2011;99(3):656-63. doi:10.1111/j.1365-2745.2011.01798.x.

10. Hoover DL, Knapp AK, Smith MD. Resistance and resilience of a grassland ecosystem to climate extremes. Ecology. 2014;95(9):2646-56. doi:10.1890/132186.1.

11. Lloret F, Escudero A, Iriondo JM, Martínez-Vilalta J, Valladares F. Extreme climatic events and vegetation: the role of stabilizing processes. Glob Chan Biol. 2012;18(3):797-805. doi:10.1111/j.1365-2486.2011.02624.x.

12. Wernberg T, Smale DA, Tuya F, Thomsen MS, Langlois TJ, De Bettignies T, et al. An extreme climatic event alters marine ecosystem structure in a global biodiversity hotspot. Nat Clim Chan. 2013;3(1):78-82. doi:10.1038/ nclimate1627.

13. Thomson JA, Burkholder DA, Heithaus MR, Fourqurean JW, Fraser MW, Statton I et al. Extreme temperatures, foundation species, and abrupt ecosystem change: an example from an iconic seagrass ecosystem. Glob Chan Biol. 2014. doi:10.1111/gcb.12694.

14. Helmuth B, Russell B, Connell S, Dong Y, Harley C, Lima F, et al. Beyond long-term averages: making biological sense of a rapidly changing world. Clim Chan Resp. 2014; (1):6. doi:10.1186/s40665-014-0006-0

15. IPCC Climate Change. The Physical Science Basis. In: Stocker TF, Qin D, Plattner GK, Tignor M, Allen SK, Boschung J, Nauels A, Xia Y, Bex V, Midgley PM, editors. Contribution of working group I to the fifth assessment report of the intergovernmental panel on climate change. Cambridge: University Press; 2013.

16. Fischer EM, Knutti R. Anthropogenic contribution to global occurrence of heavy-precipitation and high temperature extremes. Nature Clim Change. 2015. doi: 10.1038/nclimate2617.

17. Russell BD, Harley CDG, Wernberg T, Mieszkowska N, Widdicombe S, HallSpencer JM, et al. Predicting ecosystem shifts requires new approaches that integrate the effects of climate change across entire systems. Biol Lett. 2012;8(2):164-6. doi:10.1098/rsbl.2011.0779.

18. Connell SD, Kroeker K, Fabricius KE, Kline DI, Russell BD. The other ocean acidification problem: $\mathrm{CO}_{2}$ as a resource among competitors for ecosystem dominance. Phil Trans R Soc B. 2013. 368(1627). doi:10.1098/rstb.2012.0442.

19. Russell BD, Connell SD. Origins and consequences of global and local stressors: incorporating climatic and non-climatic phenomena that buffer or 
accelerate ecological change. Mar Biol. 2012;159:2633-9. doi:10.1007/ s00227-011-1863-8.

20. Brown CJ, Saunders MI, Possingham HP, Richardson AJ. Managing for interactions between local and global stressors of ecosystems. Plos One. 2013; 8(6). doi:10.1371/journal.pone.0065765.

21. Ghedini G, Russell B, Connell S. Managing local coastal stressors to reduce the ecological effects of ocean acidification and warming. Water. 2013;5(4):1653-61

22. Vinebrooke RD, Cottingham KL, Norberg MSJ, Dodson SI, Maberly SC, Sommer U. Impacts of multiple stressors on biodiversity and ecosystem functioning: the role of species co-tolerance. Oikos. 2004;104(3):451-7. doi:10.1111/j.0030-1299.2004.13255.x.

23. Crain CM, Kroeker $\mathrm{K}$, Halpern BS. Interactive and cumulative effects of multiple human stressors in marine systems. Ecol Lett. 2008;11(12):1304-15. doi:10.1111/j.1461-0248.2008.01253.x.

24. Paine RT, Tegner MJ, Johnson EA. Compounded perturbations yield ecological surprises. Ecosystems. 1998;1 (6):535-45. doi:10.1007/s100219900049.

25. Russell BD, Connell SD. Ecosystem resilience and resistance to climate change. In: Freedman B, editor. Global environmental change. Dordrecht: Springer Science \& Business Media; 2014. p. 133-9.

26. Halpern BS, Walbridge S, Selkoe KA, Kappel CV, Micheli F, D'Agrosa C, et al. A global map of human impact on marine ecosystems. Science. 2008;319(5865):948-52. doi:10.1126/science.1149345.

27. Strain EMA, Thomson RJ, Micheli F, Mancuso FP, Airoldi L. Identifying the interacting roles of stressors in driving the global loss of canopy-forming to mat-forming algae in marine ecosystems. Glob Chan Biol. 2014;20(11):3300-12. doi:10.1111/gcb.12619.

28. Brown JH, Gillooly JF, Allen AP, Savage VM, West GB. Toward a metabolic theory of ecology. Ecology. 2004;85(7):1771-89. doi:10.1890/03-9000.

29. O'Connor MI. Warming strengthens an herbivore-plant interaction. Ecology. 2009:90(2):388-98. doi:10.1890/08-0034.1.

30. Kordas RL, Harley CDG, O'Connor MI. Community ecology in a warming world: the influence of temperature on interspecific interactions in marine systems. J Exp Mar Biol Ecol. 2011;400(1-2):218-26. doi:10.1016/ j.jembe.2011.02.029.

31. Binzer A, Guill C, Brose U, Rall BC. The dynamics of food chains under climate change and nutrient enrichment. Phil Trans R Soc B. 2012;367(1605):2935-44.

32. Vasseur DA, DeLong JP, Gilbert B, Greig HS, Harley CDG, McCann KS et al. Increased temperature variation poses a greater risk to species than climate warming. Proc R Soc B. 2014; 281(1779). doi:10.1098/rspb.2013.2612.

33. Tylianakis JM, Didham RK, Bascompte J, Wardle DA. Global change and species interactions in terrestrial ecosystems. Ecol Lett. 2008;11(12):1351-63. doi:10.1111/j.1461-0248.2008.01250.x.

34. Stiling P, Moon D, Rossi A, Forkner R, Hungate BA, Day FP, et al. Direct and legacy effects of long-term elevated $\mathrm{CO}_{2}$ on fine root growth and plant-insect interactions. New Phytol. 2013;200(3):788-95. doi:10.1111/nph.12295.

35. Hemmi A, Jormalainen V. Nutrient enhancement increases performance of a marine herbivore via quality of its food alga. Ecology. 2002;83(4):1052-64. doi:10.2307/3071913

36. Sarnelle O. Nutrient enrichment and grazer effects on phytoplankton in lakes. Ecology. 1992;73(2):551-60. doi:10.2307/1940761.

37. Falkenberg $\mathrm{L}$, Connell SD, Russell $\mathrm{BD}$. Herbivory mediates the expansion of an algal habitat under nutrient and $\mathrm{CO}_{2}$ enrichment. Mar Ecol Progr Ser. 2014:497:87-92. doi:10.3354/meps 10557.

38. Lemoine NP, Burkepile DE. Temperature-induced mismatches between consumption and metabolism reduce consumer fitness. Ecology. 2012;93(11):2483-9. doi:10.2307/41739319.

39. Mertens NL, Russell BD, Connell SD. Escaping herbivory: ocean warming as a refuge for primary producers where consumer metabolism and consumption can not pursue. Oecologia. 2015. doi:10.1007/s00442-015-3438-8.

40. Falkenberg LJ, Russell BD, Connell SD. Future herbivory: the indirect effects of enriched $\mathrm{CO}_{2}$ may rival its direct effects. Mar Ecol Progr Ser. 2013;492:85-95. doi:10.3354/meps 10491

41. de Sassi C, Lewis OT, Tylianakis JM. Plant-mediated and nonadditive effects of two global change drivers on an insect herbivore community. Ecology. 2012;93(8):1892-901. doi:10.1890/11-1839.1.

42. He Q, Silliman BR. Biogeographic consequences of nutrient enrichment for plant-herbivore interactions in coastal wetlands. Ecol Lett. 2015;18(5):462-71. doi:10.1111/ele.12429.
43. Russell BD, Connell SD, Findlay HS, Tait K, Widdicombe S, Mieszkowska N: Ocean acidification and rising temperatures may increase biofilm primary productivity but decrease grazer consumption. Phil Trans R Soc B. 2013; 368(1627). doi:10.1098/rstb.2012.0438.

44. Brown CJ, Saunders MI, Possingham HP, Richardson AJ. Interactions between global and local stressors of ecosystems determine management effectiveness in cumulative impact mapping. Divers Distrib. 2014;20(5):538-46. doi:10.1111/ ddi.12159.

45. Wooldridge SA. Water quality and coral bleaching thresholds: formalising the linkage for the inshore reefs of the Great Barrier Reef Australia. Mar Poll Bull. 2009;58(5):745-51. doi:10.1016/j.marpolbul.2008.12.013.

46. O'Gorman EJ, Fitch JE, Crowe TP. Multiple anthropogenic stressors and the structural properties of food webs. Ecology. 2012;93(3):441-8.

47. Falkenberg L, Connell SD, Russell BD. Disrupting the effects of synergies between stressors: improved water quality dampens the effects of future $\mathrm{CO}_{2}$ on a marine habitat. J Appl Ecol. 2013; 50:51-8. http://dx.doi.org/ 10.1111/1365-2664.12019.

48. Russell BD, Thompson J-Al, Falkenberg LJ, Connell SD. Synergistic effects of climate change and local stressors: $\mathrm{CO}_{2}$ and nutrient-driven change in subtidal rocky habitats. Glob Chan Biol. 2009;15(9):2153-62. doi:10.1111/ j.1365-2486.2009.01886.x.

49. Connell SD, Russell BD, Turner DJ, Shepherd SA, Kildea T, Miller D, et al. Recovering a lost baseline: missing kelp forests from a metropolitan coast. Mar Ecol Progr Ser. 2008;360:63-72. doi:10.3354/meps07526.

50. Queirós AM, Fernandes JA, Faulwetter S, Nunes J, Rastrick SPS, Mieszkowska $\mathrm{N}$, et al. Scaling up experimental ocean acidification and warming research: from individuals to the ecosystem. Glob Chan Biol. 2014;21(1):130-43. doi:10.1111/gcb.12675.

51. Leung JYS, Russell BD, Connell SD, Ng JCY, Lo MMY. Acid dulls the senses: impaired locomotion and foraging performance in a marine mollusc. An Behav. 2015; 106(0):201-219. http://dx.doi.org/10.1016/j.anbehav.2015.06.004.

52. Duffy JE. Biodiversity and ecosystem function: the consumer connection. Oikos. 2002;99(2):201-19. doi:10.2307/3547902.

53. Vergés A, Steinberg PD, Hay ME, Poore AGB, Campbell AH, Ballesteros E et al. The tropicalization of temperate marine ecosystems: climate-mediated changes in herbivory and community phase shifts. Proc R Soc B: Biol Sci. 2014; 281(1789). doi:10.1098/rspb.2014.0846.

54. Ghedini G, Russell BD, Connell SD. Trophic compensation reinforces resistance: herbivory absorbs the increasing effects of multiple disturbances. Ecol Lett. 2015;18(2):182-7. doi:10.1111/ele.12405.

55. Marshall DJ, McQuaid CD. Warming reduces metabolic rate in marine snails: adaptation to fluctuating high temperatures challenges the metabolic theory of ecology. Proc R Soc B: Biol Sci. 2010. doi:10.1098/rspb.2010.1414.

56. Sentis $A$, Hemptinne J-L, Brodeur J. Effects of simulated heat waves on an experimental plant-herbivore-predator food chain. Glob Chan Biol. 2013;19(3):833-42. doi:10.1111/gcb.12094.

57. Connell SD, Foster MS, Airoldi L. What are algal turfs? Towards a better description of turfs. Mar Ecol Progr Ser. 2014;495:299-307. doi:10.3354/ meps10513.

58. Pierrot $\mathrm{D}$, Lewis $\mathrm{E}$, Wallace DWR. MS Excel program developed for $\mathrm{CO}_{2}$ system calculations. Oak Ridge, TN: Carbon Dioxide Information Analysis Center, Oak Ridge National Laboratory, US Department of Energy; 2006.

59. Mehrbach C, Culberson CH, Hawley JE, Pytkowicx RM. Measurement of the apparent dissociation constants of carbonic acid in seawater at atmospheric pressure. Limnol Oceanogr. 1973;18:897-907.

60. Dickson AG, Millero FJ. A comparison of the equilibrium constants for the dissociation of carbonic acid in seawater media. Deep Sea Res A Oceanogr Res Papers. 1987; 34(10):1733-43. http://dx.doi.org/10.1016/0198-0149(87)90021-5.

61. Quinn GP, Keough MJ. Experimental design and data analysis for biologists. Cambridge: Cambridge University Press; 2002. 